Title:

How an Age Simulation Suit affects Motor and Cognitive Performance and Self-perception in Younger Adults

\title{
Authors:
}

Janine Vieweg, Sabine Schaefer

This is an Accepted Manuscript of an article published by Taylor \& Francis in Experimental Aging Research on 23 May 2020, available online: https://www.tandfonline.com/doi/10.1080/0361073X.2020.1766299.

It is deposited under the terms of the Creative Commons Attribution-NonCommercial License (http://creativecommons.org/licenses/by-nc/4.0/), which permits non-commercial re-use, distribution, and reproduction in any medium, provided the original work is properly cited. 
How an Age Simulation Suit affects Motor and Cognitive Performance and Self-perception in Younger Adults

${ }^{1}$ Janine Vieweg and ${ }^{1}$ Sabine Schaefer

${ }^{1}$ Saarland University

M. Sc. Janine Vieweg

Saarland University

E-Mail: janine.vieweg@uni-saarland.de

Univ.-Prof. Dr. Sabine Schaefer

Saarland University

E-Mail: sabine.schaefer@uni-saarland.de

Corresponding Author:

Janine Vieweg

Saarland University

Campus Gebäude B8.1

D-66123 Saarbrücken

Phone: + 496813024624

E-Mail: janine.vieweg@uni-saarland.de

ORCID ID: https://orcid.org/0000-0002-4117-9743 


\section{How an Age Simulation Suit affects Motor and Cognitive Performance and Self-perception in Younger Adults}

Background/Study Context: We assessed the influence of wearing an Age Simulation Suit (GERT) on gross motor, fine motor and cognitive performance in healthy young adults.

Methods: In a within-subjects design, we tested 20 young adults $\left(M_{\text {age }}=22.3\right.$ years $)$ with and without the Age Simulation Suit. We assessed gross motor (Functional Fitness test) and fine motor (Purdue Pegboard test) functioning, cognitive performance (Digit Symbol Substitution test), and questionnaires on perceived physical state and mood. Gross and fine motor tests provided norms for large samples of older adults.

Results: Wearing the Age Simulation Suit leads to significant performance reductions in all task dimensions, with large effect sizes. Depending on the subtest, participants’ performances were reduced to the level of mid-50- to 85-years-olds for almost all tests of gross and fine motor performance. Mood and perceived physical state also declined while wearing the suit.

Conclusion: We argue that the GERT suit offers an attractive possibility to experimentally simulate the effects of aging-related sensory and motor losses and propose future studies with this paradigm, in the context of cognitive-motor dualtasking or motor learning.

Keywords: Age Simulation Suit, Age Comparison, Motor functioning, Cognition, Perception 


\section{Introduction}

As a global development people are getting older due to better medical healthcare and changes in educational systems and working environments. The United Nations state that “virtually all countries are experiencing population ageing” (2019, p.1), which is why healthy aging is getting more into scientific focus. An aging society can be both, for example an enrichment for the economy when designing age appropriate products, or a burden to the social - and health system when dealing with the steady cognitive and motor decline of older adults. It could be helpful to enhance our perception of the difficulties older people face in their daily lives. One possibility to experience at least some of the limitations of older age is to simulate the physical constraints of aging by wearing an Age Simulation Suit. Experiencing the effects of sensory and motor declines "first hand" by wearing such a suit could increase the understanding for seniors in younger individuals.

There is plenty of scientific evidence that aging leads to decreases in sensory, motor and cognitive domains (for overviews, see Leversen, Haga, \& Sigmundsson, 2012; S.-C. Li \& Dinse, 2002; S.-C. Li et al., 2004; Park, Polk, Mikels, Taylor, \& Marshuetz, 2001; Voelcker-Rehage, 2008). However, it is an open question whether wearing an Age Simulation Suit reduces younger adults’ performances to a similar extent.

The first attempts to simulate sensory losses that accompany the human aging process go back to the seventies (Shore, 1976). By using everyday materials, as goggles (vision), rubber gloves (tactile), ear plugs or - muffs (auditory), wheelchairs and bandages (kinesthesia), single sensory limitations were simulated to show mostly young participants what it feels like to be old.

The first full body Age Simulation Suits were invented in Germany (AgeExplorer $^{\circledR}$, Meyer-Hentschel, 2019; GERT ${ }^{\circledR}$, Moll, 2019b), Japan (LM-60 ${ }^{\circledR}$, 
Koken, 2005), and in the USA (AGNES ${ }^{\circledR}$, MIT AgeLab, 2019). These simulation suits are claimed to offer a realistic and whole-body experience to the young participants, by allowing them to simultaneously experience several consequences of physical and sensory aging (e.g., reduced strength, flexibility and sensory perception). Different sizes and individually adjustable components allow the suit to be used both by men and women, regardless of their size and weight. While all manufacturers state that their suits offer a realistic aging-experience, with components that are designed to represent the deteriorations in old age, none of them provide validation studies or empirical results to quantify their arguments. The inventor of the gerontologic simulator (GERT) states that the components of his suit cause a decline on sensorimotor functioning, equal to an aging of 30-40 years in healthy, young adults (Moll, 2019a). Given the lack of validation studies, the current paper aims to provide exact estimates of suit-induced performance changes across a variety of gross motor tasks, a fine motor task (Purdue Pegboard test), and a cognitive task (Digit Symbol Substitution test).

Addressing the needs of older adults by using Age Simulation Suits is of interest to various areas. In ergonomics, for instance, the workplace and processes should be adequate to the needs of older workers. In addition, the designed products must meet the cognitive and motor abilities of older customers. Scherf (2014) and Schneider (2011) used Age Simulation Suits for studies in the automotive industry. Schneider (2011) wanted the management and workers of an automobile supplier to experience the challenging manufacturing processes with advanced age. Scherf (2014) evaluated the effects of different Age Simulation Suit-modules on the installation performance of young (20-30-years-old) and older (50-60-years-old) assembly-workers of a big German automobile manufacturer, and demonstrated comparable performances of the young workers, wearing the least restrictive suit, and the older workers, wearing no suit. 
Another field of interest is the health care or medical sector. Promoting empathy is a big concern in the education of medical professions, like doctors or nurses, and especially in geriatric medicine. Simulation trainings, like role-plays, simulation mannequins or the teaching method of "Instant Aging”, represent an essential part of the curriculum for these professions (Braude et al., 2015; Fisher \& Walker, 2013). Instant Aging creates a teaching and learning environment to experience the physical challenges of advanced age and/or certain typical diseases like vision and hearing loss, arthritis, hemiparesis, diabetes mellitus and Parkinson (Filz, 2009; Koytek, 2008; Kwetkat, Swoboda, \& Singler, 2011). Qureshi, Jones, Adamson, and Ogundipe (2017) and Tremayne, Burdett, and Utecht (2011) used an Age Simulation Suit in everyday and working specific tasks to challenge the medical and nursing students' perspective of older patients and to promote awareness and understanding for the constraints of the older patients. Oral or written feedback of the young participants was very positive and highlighted the vivid and memorable effects of the simulation (Clark, Foos, \& Faucher, 1995; Fisher \& Walker, 2013; Oakley et al., 2014; Qureshi et al., 2017; Wood, 2003). A systematic review by Tullo, Spencer, and Allan (2010) states that these innovative teaching interventions have the potential to improve the knowledge and attitude of young medical students towards older patients, and that they are beneficial to promote empathy and a perspective takeover in these professions (but see Alfarah, Schünemann, \& Akl, 2010, for a critical review of the effects of role playing interventions in geriatric medical education).

Previous studies focused on age simulation as a teaching and learning tool and therefore collected qualitative data about the effect of the intervention, usually by asking for self-reports. To our knowledge, very few studies investigated the quantitative performance changes in certain tasks due to wearing an Age Simulation Suit (Lauenroth, Schulze, Ioannidis, Simm, \& Schwesig, 2017; Lavallière et al., 2016; 
Scherf, 2014; Zijlstra, Hagedoorn, Krijnen, van der Schans, \& Mobach, 2016). Zijlstra et al. (2016) investigated the effect of an age simulation on wayfinding. They found that wearing a suit results in lower speed and higher heart and respiratory rates in young adults compared to not wearing the suit. Lavallière et al. (2016) studied how an Age Simulation Suit influences several clinical tests (postural balance, neck/shoulder range of motion, low back/hamstring flexibility and 10m-walk) and an experiential learning task. Young adults wearing the simulation suit showed a significant decline in almost all clinical tests, including a reduced velocity and an increased number of steps and time to walk the 10m distance. The effects of an Age Simulation Suit on several gait parameters as velocity, step length, step time and base width were analyzed by Lauenroth et al. (2017). Their results for step length and velocity indicated a reduction similar to an "age increase of 20 to 25 years” (p. 5) of young adults wearing the suit compared to the results of older adults.

To summarize, previous studies showed performance or physiological declines when wearing an Age Simulation Suit, but only Scherf (2014) and Lauenroth et al. (2017) compared the performances of younger adults wearing an Age Simulation Suit with the performances of older adults within the same tasks. These results consistently show performance decrements, but do not indicate a certain target age that can be simulated by wearing an Age Simulation Suit. We argue that effects of Age Simulation Suits should be investigated in different domains of functioning, like gross motor tasks, fine motor tasks, and even cognitive performances and self-perception. The Functional Fitness test (Rikli \& Jones, 1999a, 1999b) and the Purdue Pegboard test (Lafayette Instrument, 2015) are well established tests for gross- and fine motor functioning. They assess physical resources that are necessary to perform everyday tasks, such as to go shopping, or to thread a thread into a needle. Both tests provide norms for seniors, 
allowing us to empirically measure whether the performances of young adults wearing the suit can be compared to the performances of older adults of specific age ranges.

There is empirical evidence for gender differences for many subtasks of these tests. For the Purdue Pegboard test, women perform better than men for all subtasks (Agnew, Bolla-Wilson, Kawas, \& Bleecker, 1988; Sattler \& Engelhardt, 1982; Yeudall, Fromm, Reddon, \& Stefanyk, 1986). On the Functional Fitness test (Rikli \& Jones, 1999b), men score better on strength, aerobic endurance, and agility/balance compared to women, wheras women show better flexibility. We use the norm data for both genders, and recruited equal numbers of males and females for our study.

In addition to changes in standardized performance measures, wearing an Age Simulation Suit can also affect mood and perceived physical state. We hypothesize that wearing the suit and perfoming a variety of tasks will be rather challenging and exhausting, so mood and perceived physical state will probably deteriorate in this condition.

The purpose of the present study was twofold: a) In a within-subjects design, we wanted to investigate if an Age Simulation Suit affects various performance domains, so we chose motor and cognitive tasks, as well as self-perceptions of physical state and mood. b) We wanted to evaluate the extent to which performances of young participants are reduced by wearing the suit, and whether young adults actually reach the performance level of older adults when wearing the suit. For the motor domain, we chose the Functional Fitness test (gross motor skills) and the Purdue Pegboard test (fine motor skills) to compare the data of the young participants wearing the suit to published age norms on the respective tests. We predict that wearing an Age Simulation Suit results in decrements in motor and cognitive performances, and influences perceived physical state and mood. 


\section{Methods}

\section{Participants}

Since the manufacturer of the GERT suit (Moll, 2019a) claims that the suit causes performance decrements corresponding to 30-40 years of chronological age, we expected large effect sizes. We also argue that large effects are necessary if such suits are to be useful tools in future research. We conducted an a priori power analysis using G*Power3 (Faul, Erdfelder, Lang, \& Buchner, 2007) to test the performance difference between the suit and no suit-condition, with a large effect size $(f=.40)$, an alpha of .05, and a correlation among repeated measures of $r=.50$. Result showed that a total sample of 19 participants was required to achieve a power of .90 .

We recruited twenty young adults ( $M_{\text {age }}=22.3$ years, 10 women). All participants had no history of neurological disease or musculoskeletal dysfunctions and had normal or corrected-to-normal vision. The participants had no prior experience with the tasks and were not aware of the specific purpose of the study. All participants except one were right-hand dominant as determined by the Edinburgh Handedness Inventory (Oldfield, 1971) prior to the experiment. Subjects were undergraduate sport students and were given course credit for their participation. Informed consent was obtained prior to participation in the experiment. The study was approved by the Ethics committee of Saarland University.

\section{Age Simulation Suit}

As an Age Simulation Suit, the model GERT (see Figure 1) from Moll (2019b) was used. This suit is designed to simulate consequences of physical aging on multiple dimensions. Reduced sensory acuity and tactile perception, by wearing disposable plastic gloves, and reductions in vision and hearing are intended. Colored glasses narrow the field of vision and create a blurry image. The earmuffs affect hearing, especially for higher frequencies. Bandages on elbows, knees and wrists should reduce 
flexibility and range of motion of these joints. The plastic gloves and the fingerless leather gloves restrict the grip ability and agility of the fingers. Note that the leather gloves only partially cover the fingers so as not to interfere with the reduced tactile perception simulated by the plastic gloves worn under the leather. A neck ruff leads to decreased agility of the head. Additional weights, $1.5 \mathrm{~kg}$ on each wrist, $2.3 \mathrm{~kg}$ on each ankle and a $10 \mathrm{~kg}$ upper-body-vest, affect strength and coordination abilities. Decreased balancing ability and insecure standing and gait are intended by wearing overshoes, with a $1.5 \mathrm{~cm}$ thick soft foam sole (see Figure 1).

[Insert Figure 1 here]

\section{Experimental group, task and procedure}

All participants performed two testing sessions, approximately 24 hours apart, one with the Age Simulation Suit and one without the suit. The order of testing sessions was counterbalanced, and males and females were distributed equally across the two counterbalancing conditions. In both conditions, the current physical feelings of the participants were assessed with the Perceived Physical State ("PEPS", Kleinert, 2006), a questionnaire of 20 adjectives representing four dimensions: physical energy (e.g., flabby, washed out), physical fitness (e.g., well trained, strong), physical flexibility (e.g., flexible, elastic), and physical health (e.g., sick, injured) (Kleinert, 2007). The perceived physical state was assessed with a six-point rating scale ranging from "not at all" (0) to "totally" (5). The current mood state of the participants was measured with the short Mood Scale ("MS", Wilhelm \& Schoebi, 2007), a questionnaire of six bipolar items that measures three dimensions of mood: energetic arousal (e.g., tired - awake), valence (e.g., content - discontent) and calmness (e.g., relaxed - tense). Afterwards participants performed the Functional Fitness test ("FFT", Rikli \& Jones, 1999a, 
1999b), a screening battery to assess four motor dimensions: strength, flexibility, aerobic endurance and balance/agility.

\section{Strength}

The numbers of full chair stands with arms folded across the chest (leg strength) and the numbers of biceps curls holding a 2.9 kilogram (women) or 4.4 kilogram (men) hand weight (arm strength) were assessed, with 30 seconds for each test.

\section{Flexibility}

For hip flexibility, participants sat at the edge of a chair with one extended leg and tried to reach as far forward as possible toward (or beyond) the toes (chair sit-andreach task). Distance was measured from the extended fingers to the tip of the toe. Note, positive numbers indicate reaching beyond the toes and negative numbers mean reaching short of the toes. Shoulder flexibility was assessed by trying to reach the middle finger of the other hand behind the back with one hand reaching over the shoulder and one up the middle of the back (back-scratch task). Again, the distance (or amount of overlap) between both middle fingers was measured. Positive numbers indicate that the fingers overlap, and negative numbers that the fingers do not touch. Both flexibility tasks were performed with the more mobile limb and with two attempts for each task. The better attempt was scored.

\section{Aerobic endurance}

Participants had to step for 2 minutes, by raising each knee to a minimum height as often as possible. The minimum height represents half of the length of the thigh, measured as the distance between the kneecap and the anterior hip bone, and was calculated individually for each participant. The individual height was marked on the wall as a reference point.

\section{Balance and agility}

Balance and agility were tested with the 8-feet timed-up-and-go task (“TUG”). 
Participants rise up from a chair, walk a distance of 8-feet and circle a pylon, and sit down again in the shortest time possible. The better out of two attempts was scored.

The FFT was assessed with the following task order in each session: leg strength, arm strength, aerobic endurance, hip flexibility, shoulder flexibility and balance/agility. We compared the FFT-results of the young adults wearing the suit with normative data from Rikli and Jones (1999b), who tested over 7.000 communityresiding American older adults aged 60-94 years.

As a cognitive measure the Digit-Symbol Substitution test ("DS", Wechsler, 1981) was chosen to assess perceptual speed. Participants were presented with combinations of digits and abstract symbols. Test sheets contain rows of digits in random order, with blank spaces underneath. Participants are asked to fill in as many blank spaces as possible with the correct symbol in 90 seconds. After the DS, all participants answered the PEPS and MS for a second time, so that both questionnaires were assessed at the beginning and middle of each testing session.

Fine motor skills were assessed with a shirt-buttoning task and the Purdue Pegboard test (“PPT”, Lafayette Instrument, 2015). In the buttoning-task, participants must button up seven buttons of a shirt and open them again as often as possible in 60 seconds.

The PPT measures unimanual and bimanual finger and hand dexterity with four subtests. The pegboard consists of two parallel rows of 25 holes each. Participants have to place as many metal pins as possible in a row, either with their dominant hand, their non-dominant hand, or with both hands, within a 30-second time period (first three subtests). In the fourth subtest participants use both hands alternately to construct assemblies, which consist of four elements (a pin, a washer, a collar, and a second washer). Participants must complete as many assemblies as possible within one minute. We compared the PPT-performances of the young participants wearing the Age 
Simulation Suit with normative data from Agnew et al. (1988) based on 212 healthy 4085-year-old adults.

\section{Statistical analysis}

Statistical analyses were computed with SPSS for Windows version 24.0 (IBM Corp., Armonk, NY, USA). Analyses of task performances with the Age Simulation Suit and without the suit were computed using mixed-design analyses of variance (ANOVA) with suit (2: suit, no suit) as within-subjects factor and gender (2: female, male) as between-subjects factor. Analyses of the questionnaires were computed using mixed-design ANOVAs with suit (2: suit, no suit) and order (2: beginning vs. middle of the respective session) as within-subjects factors and gender (2: female, male) as between-subjects factor. The effect size partial eta square $\left(\eta_{\mathrm{p}}{ }^{2}\right)$ was determined for all significant effects (Cohen, 1988). The alpha level of .05 was used to interpret statistical significance. Significant main effects and interactions effects were followed by simple main effect analyses.

\section{Results}

Table 1 presents mean performances without the suit, when wearing the suit, the performance decrement expressed as a percentage score, and the age norms of the respective subtest for males and females in the FFT test. For the percentage scores, the difference from "Suit” to "No Suit”, divided by "No Suit”, was calculated. Multiplication by 100 yielded the respective \%-values. Table 2 presents the same data for the PPT. Figure 2 shows the performance decrements for all subtests of the gross and fine motor tasks, the cognitive performance, and the ratings of perceived physical and emotional state. Wearing the Age Simulation Suit (ASS) leads to significant performance reductions in all measures. 
[Insert Figure 2 here]

\section{Functional Fitness test}

\section{Strength}

Leg

The analysis of full stands detected a significant main effect of suit, $F(1,18)=$ $35.10, p<.001, \eta_{\mathrm{p}}{ }^{2}=.66$. The main effect of gender and the interaction of suit $\times$ gender failed to reach significance. Despite the pronounced decrements while wearing the suit, in comparison to normative data from Rikli and Jones (1999b), the performance of female and male participants wearing the ASS was still much better than the performance of 60-64-year-old community-residing adults (see Table 1). Arm

The results of the numbers of biceps curls showed a significant main effect of suit, $F(1,18)=41.65, p<.001, \eta_{\mathrm{p}}{ }^{2}=.70$, and gender, $F(1,18)=6.05, p<.05, \eta_{\mathrm{p}}{ }^{2}=$ .25. The interaction of suit $\times$ gender did not reach significance. Men achieved more biceps curls than women. Results of young men wearing the suit are slightly better than for 60-64-year-old men. They can be estimated to represent performances of men in their mid-fifties. The results of the women are comparable to 60-64-year-old women (see Table 1).

\section{Aerobic endurance}

\section{Stepping}

The analysis detected a significant main effect of suit, $F(1,18)=137.83, p<$ $.001, \eta_{\mathrm{p}}{ }^{2}=.88$, and gender, $F(1,18)=4.63, p<.05, \eta_{\mathrm{p}}{ }^{2}=.21$, but no significant interaction of suit $\times$ gender. The main effect of gender revealed a worse performance of women compared to men. Young women and men wearing the ASS showed better results than 60-64-year-olds, with women probably being roughly comparable to 
women in their late fifties and men being comparable to men in their early fifties (see Table 1).

\section{Flexibility}

Hip

The analysis detected a significant main effect of suit, $F(1,18)=19.29, p<.001$, $\eta_{\mathrm{p}}{ }^{2}=.52$, but no significant main effect of gender, and no interaction of suit $\times$ gender. The performance of female and male participants with the ASS was much better than comparable results of 60-64-year-olds (see Table 1).

Shoulder

The analysis detected a significant effect of suit, $F(1,18)=207.92, p<.001, \eta_{\mathrm{p}}{ }^{2}$ $=.92$. The main effect of gender and the interaction of suit $\times$ gender failed to reach significance. As shown in Table 1, while wearing the ASS, females and males perform at the level of 65-69-year-olds.

\section{Balance/Agility}

TUG

For the TUG, there was a significant effect of suit, $F(1,18)=208.30, p<.001$, $\eta_{\mathrm{p}}{ }^{2}=.92$, but no significant effect for gender, and no interaction of suit $\times$ gender. The performances with the ASS of the young female and male participants are better than the results of 60-64-year-old adults, and can be estimated to be equivalent to middleaged performances (see Table 1).

[Insert Table 1 here]

\section{Fine motor tasks}

\section{Purdue Pegboard test}

Dominant hand 
The analysis showed a significant main effect of suit, $F(1,18)=127.08, p<$ $.001, \eta_{\mathrm{p}}{ }^{2}=.88$. The effect of gender and the interaction of suit $\times$ gender did not reach significance. The comparison with normative data from Agnew and colleagues (1988) showed that wearing the ASS resulted in performances that are comparable to men in their late seventies or early eighties and to 80-89-year-old women (see Table 2).

\section{Non-dominant hand}

The results indicated a significant main effect of suit, $F(1,18)=105.50, p<$ $.001, \eta_{\mathrm{p}}{ }^{2}=.85$, but no significant effect for gender or for the interaction of suit $\times$ gender. The results of the young men and women wearing the ASS are comparable to the results of older adults who are about eighty years old (see Table 2).

\section{Both hands}

The analysis detected a significant main effect of suit, $F(1,18)=187.74, p<$ $.001, \eta_{\mathrm{p}}{ }^{2}=.91$, gender, $F(1,18)=5.85, p<.05, \eta_{\mathrm{p}}{ }^{2}=.25$, and a significant interaction of suit $\times$ gender, $F(1,18)=7.20, p<.05, \eta_{\mathrm{p}}{ }^{2}=.29$. The main effect of gender showed a superior performance of women in comparison to men. Simple main effect analysis for suit across gender showed a significant effect for the no suit-condition, with women ( $M$ $=13.90, S D=1.40)$ performing superior in contrast to men $(M=11.80, S D=1.20)$, $t(18)=3.63, p<.01$, and no significant gender difference in the suit-condition. The performance of the female participants is comparable to results of women who are about eighty years old and the male participants are comparable to men in their early eighties (see Table 2).

Assembly

The analysis showed a significant main effect of suit, $F(1,18)=229.87, p<$ $.001, \eta_{\mathrm{p}}{ }^{2}=.93$. The main effect of gender and the interaction of suit $\times$ gender failed to reach significance. The results of both young men and women with the ASS are comparable to older adults being about eighty years old (see Table 2). 
[Insert Table 2 here]

\section{Shirt-buttoning}

The analyses were conducted with nineteen participants because one male participant did not fit into the shirt. The results indicated a significant main effect of suit, $F(1,18)=162.55, p<.001, \eta_{\mathrm{p}}{ }^{2}=.90$, but no significant effects of gender, and no interaction of suit $\times$ gender. The main effect of suit revealed a performance decrease, with participants buttoning 25 buttons $(S D=4.85)$ in the no suit-condition, and only 9 buttons $(S D=4.06)$ when wearing the suit.

\section{Cognitive measure and questionnaires}

\section{Digit Symbol}

For Digit Symbol, there was a significant main effect of suit, $F(1,18)=13.84, p$ $<.01, \eta_{\mathrm{p}}^{2}=.44$, but no significant effects were revealed for gender or for the interaction of suit $\times$ gender.

\section{Physical and Mood State}

Because of missing data from one participant, nineteen participants were analyzed. Analyses of the questionnaires were computed using mixed-design ANOVAs with suit (2) and order (2) as within-subjects factors and gender (2) as between-subjects factor. For the current Perceived Physical State (PEPS) and the current Mood State (MS) questionnaires, a significant main effect of suit appeared for all dimensions. Except for the dimension "energetic arousal” of the MS, a significant main effect of order was revealed for all dimensions of both questionnaires. The main effect of gender failed to reach significance for both questionnaires. The interaction of suit $\times$ order was significant for all dimensions of the two questionnaires (see Table 3). 
The main effect of order indicated a decrease in the perceived physical and emotional state after performing the FFT and the DS, in comparison to the beginning of the session. As can be seen in Table 3, the interaction of suit and order was due to decreases in perceived physical state and mood in the session with the suit, while there were no differences between the beginning and middle of the session in the no suitcondition. The only exception was the subscale "activity" of the PEPS, $t(18)=2.60, p<$ .05 , which showed a reduction from the beginning $(M=3.95, S D=0.90)$ to the middle of the session $(M=3.54, S D=1.08)$ in the no suit-session as well.

[Insert Table 3 here]

\section{Discussion}

In the present experiment we investigated the effects of an Age Simulation Suit on multiple performance domains, namely motor and cognitive tasks, as well as selfperception of physical and emotional state. As predicted, wearing an Age Simulation Suit resulted in pronounced performance decrements in gross and fine motor tasks and in a cognitive task. When performance reductions are expressed in percentages, participants lose on average between 12 and 26 percent in the gross motor tasks and between 20 and 30 percent in the fine motor tasks when wearing the suit. The only exception is the shoulder flexibility test, for which performances deteriorate by up to $350 \%$. Wearing the suit also influenced the perception of physical state and mood of the young adults.

Compared to age norms of the Functional Fitness Test (Rikli \& Jones, 1999b), wearing the suit reduced young adults’ performances for "leg strength”, "hip flexibility” and the "balance/agility", but performances were still higher than in the age norms for 60-64-year-olds. Performances for the subtests “arm strength” and “2 min-stepping” 
were still better than performances of 60-64-year-old community-residing women and men, but the differences to the 60-64-year-old sample were attenuated. Performances for the "shoulder flexibility" test were more impaired by wearing the suit, and were comparable to 65-69-year-old women and men.

For the fine motor control required in the Purdue Pegboard test, the performances of the young adults wearing the Age Simulation Suit were comparable to the performances of about eighty-year-old adults in the subtests "non-dominant hand" and "assembly”. For the “dominant hand” and "both hands”, their performances were comparable to performances of older adults in their late seventies or early eighties (see Agnew et al., 1988).

The heterogeneous pattern of performance decrements with regard to the published age norms can be interpreted in various ways. The superior performances in some subtests of the FFT could be due to the selection of the participants. We only tested sport students who participate in at least one sport or fitness course a week, which might lead to a better "overall” fitness, in contrast to a less fit and also more heterogeneous peer group. In addition, some subtests might be more demanding than others, involving whole-body movements. For instance, the number of full stands within $30 \mathrm{sec}$ measures isolated leg strength, while 2 min-stepping involves the whole body, by coordinating arm and leg movements, and is made more difficult by carrying all the weights.

We only assessed one specific Age Simulation Suit (GERT), and do not know whether our findings would generalize to other models. We assume that not all tasks are restricted equally by the components of the suit. For example, the performance decrements in the "shoulder flexibility" task are possibly also influenced by the size of the weights around participants' wrists. These biomechanical constraints could make it harder to reach the other hand. The fine motor tasks of the Purdue Pegboard test are 
made more difficult in several ways. The tactile perception of the fingertips, the strength and mobility of the finger and hand, as well as the ability to coordinate the grasping movement are reduced simultaneously, by wearing two types of gloves. In addition, the reduced vision caused by the colored glasses could also have a major influence on these subtests. Future research using a systematic manipulation of the individual components is necessary to disentangle their influence on specific types of performances.

We also found performance declines in cognition, as measured by the performance in the Digit Symbol Substitution test. This paper-and-pencil test requires to perceive a target symbol and to accurately and quickly copy it into the respective field. The Digit Symbol Substitution test measures perception and processing speed, which are seen as predominantly cognitive functions (see S.-C. Li et al., 2004; Wechsler, 1981). However, performance on the test is also affected by sensory and motor processes. We assume that performance declines in our paradigm were mainly caused by visuomotor aspects, as changes in visual acuity and in the fine-motor control of fingers and hands. However, it is possible that other cognitive tasks requiring less precise visual input and less or no fine motor control also suffer from wearing an Age Simulation Suit. In future research, the Age Simulation Suit can illustrate the importance of sensorimotor processes even in predominantly cognitive tasks. The suit has no direct influence on the neuronal integrity of the brain, but only influences sensory and motor processes. Concerning age-related cognitive and motor decline, future research with this paradigm can hopefully contribute to the debates on common or specific causes for cognitive and motor declines in older ages (Cai, Chan, Yan, \& Peng, 2014; K. Z. H. Li \& Lindenberger, 2002; Lindenberger, Scherer, \& Baltes, 2001; Schaefer, Huxhold, \& Lindenberger, 2006), by offering an attractive possibility to experimentally influence some of the underlying factors. This approach could also help 
to identify tasks that represent a "purer" measure of cognition than some of the classic paper-and-pencil measures that are often used in neuropsychological assessments.

In a similar vein, age simulations could be used in research on cognitive-motor dual-tasking across the adult lifespan. Older adults have often been shown to have higher decrements when performing a cognitive and a motor task simultaneously, since they have to invest attentional resources into seemingly automatized motor tasks. They also tend to prioritize the motor tasks (Al-Yahya et al., 2011; K. Z. H. Li, Lindenberger, Freund, \& Baltes, 2001; Schaefer, 2014; Woollacott \& Shumway-Cook, 2002). Do young adults behave similarly when wearing an Age Simulation Suit? Does wearing such a suit also influence their strategic decisions, for example when choosing a suitable level of task-difficulties (Riediger, Li, \& Lindenberger, 2006)?

Concerning motor learning, can the Age Simulation Suit slow down the process of motor learning and if so, how long would it take for the young adults to get used to these restrictions? Do they develop alternative strategies to deal with the limitations in an early learning stage (see Brand \& de Oliveira, 2017; van Andel, Cole, \& Pepping, 2017, for literature on recalibration), or are there motor learning tasks for which the restrictions cannot be compensated for?

Changes in the current physical and mood state of the young adults demonstrate that the Age Simulation Suit has a strong impact on the participants' self-perception. Feeling like an older adult, both emotionally and physically, has the potential to create awareness of the physical but also the psychological changes and challenges of aging. Such an experience can improve the attitude towards older adults, as several studies have previously shown (Qureshi et al., 2017; Tremayne et al., 2011; Tullo et al., 2010).

In conclusion the Age Simulation Suit GERT offers young healthy adults the opportunity to experience the process of normal physical and sensory aging, by reducing their performances in fine and gross motor and cognitive tasks, as well as 
influencing their physical and emotional self-perception. Our results show that wearing the GERT does not lead to a general aging of 30-40 years, as the manufacturer claims. Rather the performance decrements are dependent on the chosen abilities and tasks. For the Functional Fitness test the manufacturer's age specification roughly fits, whereas the performance decrements of the Purdue Pegboard test are much stronger. This performance variability could be seen as a good illustration of the real process of aging, which differs considerably among older people. Becoming older sometimes means facing serious health conditions and maybe losing one's independence, but it could also reflect a "successful aging” with fewer declines in physiological and social functioning and positive perceptions of life-satisfaction and well-being (see Cosco, Prina, Perales, Stephan, \& Brayne, 2014, for a review). Having this in mind, the Age Simulation Suit offers a "general" experience of older age, representing the most common physical and sensory losses when becoming older. Therefore, when applying the suit in a particular setting, for example to simulate a specific age or level of difficulty, it may be necessary to make some adjustments to it (see also Scherf, 2014).

\section{Acknowledgement}

We would like to thank Daniel Bach and Manuel Zachej for their help in data collection and data entry. We also want to thank Gianluca Amico, Daniel Bill, and Christian Kaczmarek for helpful discussions and Peter Leinen for being our photo model. If you are interested in the raw data of this study, please don't hesitate to contact us.

\section{Conflict of Interest}

We have no conflict of interest to declare.

\section{Funding}

None reported. 


\section{References}

Agnew, J., Bolla-Wilson, K., Kawas, C. H., \& Bleecker, M. L. (1988). Purdue pegboard age and sex norms for people 40 years old and older. Developmental Neuropsychology, 4(1), 29-35. doi:10.1080/87565648809540388

Al-Yahya, E., Dawes, H., Smith, L., Dennis, A., Howells, K., \& Cockburn, J. (2011).

Cognitive motor interference while walking: A systematic review and meta-analysis. Neuroscience ad Biobehavioral Reviews, 35, 715-728.

doi:10.1016/j.neubiorev.2010.08.008

Brand, M. T., \& de Oliveira, R. F. (2017). Recalibration in functional perceptual-motor tasks: A systematic review. Human Movement Science, 56, 54-70. doi:10.1016/j.humov.2017.10.020

Braude, P., Reedy, G., Dasgupta, D., Dimmock, V., Jaye, P., \& Birns, J. (2015). Evaluation of a simulation training programme for geriatric medicine. Age and Ageing, 44(4), 677682. doi:10.1093/ageing/afv049

Cai, L., Chan, J. S. Y., Yan, J. H., \& Peng, K. (2014). Brain plasticity and motor practice in cognitive aging. Frontiers in Aging Neuroscience, 6(31), 1-12. doi:10.3389/fnagi.2014.00031

Clark, M. C., Foos, P. W., \& Faucher, M. H. (1995). You can touch this: Simulation exercises for aging and disability. Educational Gerontology: An International Quarterly, 21(7), 643-651. doi:10.1080/0360127950210701

Cohen, J. (1988). Statistical power analysis for the behavioral sciences (2nd ed.). Hillsdale, NJ: Erlbaum.

Cosco, T. D., Prina, A. M., Perales, J., Stephan, B. C. M., \& Brayne, C. (2014). Operational definitions of successful aging: A systematic review. International Psychogeriatric Association, 26(3), 373-381. doi:10.1017/S1041610213002287 
Faul, F., Erdfelder, E., Lang, A.-G., \& Buchner, A. (2007). G*3 Power: A flexible statistical power analysis program for the social, behavioral, and biomedical sciences. Behavior Research Methods, 39, 175-191. doi: 10.3758/BF03193146

Filz, S. A. (2009). „Instant Aging“ - Selbsterfahrung des Alterns ["Instant Aging” - Selfawareness of aging]. Julius-Maximilians-Universität Würzburg, Deutschland. Retrieved from https://opus.bibliothek.uni-wuerzburg.de/opus4wuerzburg/frontdoor/deliver/index/docId/3405/file/Doktorarbeit_S.Allan_Filz.pdf

Fisher, J. M., \& Walker, R. W. (2013). A new age approach to an age old problem: using simulation to teach geriatric medicine to medical students. Age and Ageing, 43(3), 424-428. doi:10.1093/ageing/aft200

Kleinert, J. (2006). Adjektivliste zur Erfassung der Wahrgenommenen Körperlichen Verfassung (WKV): Skalenkonstruktion und erste psychometrische Befunde [Adjective list for assessing Perceived Physical State (PEPS)]. Zeitschrift für Sportpsychologie, 13(4), 156-164. doi:10.1026/1612-5010.13.4.156

Kleinert, J. (2007). Mood states and perceived physical states as short term predictors of sport injuries: Two prospective studies. International Journal of Sport and Exercise Psychology, 5(4), 340-351. doi:10.1080/1612197x.2007.9671840

Koken. (2005). The aged simulation set. Retrieved from http://www.kokenmpc.co.jp/english/products/life_simulation_models/nursing_educati on/lm-060/index.html

Koytek, B. (2008). „Instant Aging“ - Ein neues Kurskonzept für den allgemeinmedizinischen Unterricht ["Instant Aging" - A new course concept for general medical education]. Georg-August-Universität zu Göttingen, Deutschland. Retrieved from https://alterssimulationsanzug.com/wp-content/uploads/2018/07/Koytek-BarbaraInstant-Aging-Diss-2008-1.pdf 
Kwetkat, A., Swoboda, W., \& Singler, K. (2011). Instant Aging - Ein Erfahrungsbericht aus der medizinischen Lehre [Instant Aging - A report from the medical teaching]. Zeitschrift für Medizinische Psychologie, 20(4), 185-187. doi:10.3233/ZMP-20112032

Lafayette Instrument. (2015). Purdue Pegboard Test. User instructions. Retrieved from http://www.limef.com/downloads/MAN-32020A-forpdf-rev0.pdf

Lauenroth, A., Schulze, S., Ioannidis, A., Simm, A., \& Schwesig, R. (2017). Effect of an age simulation suit on younger adults' gait performance compared to older adults' normal gait. Research in Gerontological Nursing, 10(5), 227-233. doi:10.3928/1940492120170831-04

Lavallière, M., D'Ambrosio, L., Gennis, A., Burstein, A., Godfrey, K. M., Waerstad, H., .. . Coughlin, J. F. (2016). Walking a mile in another's shoes: The impact of wearing an age suit. Gerontology \& Geriatrics Education, 00, 1-21.

doi:10.1080/02701960.2015.1079706

Leversen, J. S. R., Haga, M., \& Sigmundsson, H. (2012). From children to adults: Motor performance across the life-span. Plos One, 7, e38830. doi:10.1371/journal.pone.0038830

Li, K. Z. H., \& Lindenberger, U. (2002). Relations between aging sensory/sensorimotor and cognitive functions. Neuroscience and Biobehavioral Reviews, 26, 777-783.

Li, K. Z. H., Lindenberger, U., Freund, A. M., \& Baltes, P. B. (2001). Walking while memorizing: Age-related differences in compensatory behavior. Psychological Science, 12(3), 230-237.

Li, S.-C., \& Dinse, H. R. (2002). Aging of the brain, sensorimotor, and cognitive processes. Neuroscience and Biobehavioral Reviews, 26, 729-732. 
Li, S.-C., Lindenberger, U., Hommel, B., Aschersleben, G., Prinz, W., \& Baltes, P. B. (2004). Transformations in the couplings among intellectual abilities and constituent cognitive processes across the life span. Psychological Science, 15(3), 155-163.

Lindenberger, U., Scherer, H., \& Baltes, P. B. (2001). The strong connection between sensory and cognitive performance in old age: Not due to sensory acuity reductions operating during cognitive assessment. Psychology and Aging, 16, 196-205.

Meyer-Hentschel. (2019). Altersanzug mieten [Rent an age suit]. Retrieved from https://ageexplorer.com/altersanzug-mieten-2/

MIT AgeLab. (2019). AGNES (Age Gain Now Empathy System). Retrieved from http://agelab.mit.edu/agnes-age-gain-now-empathy-system

Moll, W. (2019b). GERonTologic simulator GERT. Retrieved from http://www.agesimulation-suit.com/

Oakley, R., Pattinson, J., Goldberg, S., Daunt, L., Samra, R., Masud, T., . . Gordon, A. L. (2014). Equipping tomorrow's doctors for the patients of today. Age and Ageing, 43(4), 442-447. doi:10.1093/ageing/afu077

Oldfield, R. C. (1971). The assessment and analysis of handedness: The Edinburgh inventory. Neuropsychologia, 9(1), 97-113. doi:10.1016/0028-3932(71)90067-4

Park, D. C., Polk, T. A., Mikels, J. A., Taylor, S. F., \& Marshuetz, C. (2001). Cerebral aging: integration of brain and behavioral models of cognitive function. Dialogues in Clinical Neuroscience, 3(3), 151-165.

Qureshi, S., Jones, H., Adamson, J., \& Ogundipe, O. A. (2017). Ageing simulation for promoting empathy in medical students. BMJ Simulation and Technology Enhanced Learning, 3(2), 79-81. doi:10.1136/bmjstel-2016-000161

Riediger, M., Li, S.-C., \& Lindenberger, U. (2006). Selection, optimization, and compensation as developmental mechanisms of adaptive resource allocation: Review 
and preview. In J. E. Birren \& K. W. Schaie (Eds.), Handbook of the psychology of aging (6 ed., pp. 289-313). Amsterdam: Elsevier.

Rikli, R. E., \& Jones, C. J. (1999a). Development and Validation of a Functional Fitness Test for Community-Residing Older Adults. Journal of Aging and Physical Activity, 7, 129-161.

Rikli, R. E., \& Jones, C. J. (1999b). Functional Fitness Normative Scores for CommunityResiding Older Adults, Ages 60-94. Journal of Aging and Physical Activity, 7, 162181.

Sattler, J. M., \& Engelhardt, J. (1982). Sex differences on purdue pegboard norms for children. Journal of Clinical Child Psychology, 11(1), 72-73. doi:10.1080/15374418209533066

Schaefer, S. (2014). The ecological approach to cognitive-motor dual-tasking: Findings on the effects of expertise and age. Frontiers in Psychology, 5, 1-9. doi:10.3389/fpsyg.2014.01167

Schaefer, S., Huxhold, O., \& Lindenberger, U. (2006). Healthy mind in healthy body? A review of sensorimotor-cognitive interdependencies in old age. European Review of Aging and Physical Activity, 3, 45-54. doi:10.1007/s11556-006-0007-5

Scherf, C. (2014). Entwicklung, Herstellung und Evaluation des Modularen Alterssimulationsanzugs ${ }^{\text {eXtra }}$ (MAX) [Development, production and evaluation of the modular Age Simulation Suit $\left.{ }^{\text {extra }}(M A X)\right]$. Technische Universität Chemnitz, Universitätsverlag Chemnitz, Deutschland.

Schneider, C. (2011). Aha-Erlebnis im Altersanzug: Demografieprojekt in der Automobilindustrie [Aha-experience in an age suit: Demography project in the automative industry]. physiopraxis, 9(2), 42-44. doi:10.1055/s-0031-1273186

Shore, H. (1976). Designing a training program for understanding sensory losses in aging. The Gerontologist, 16(2), 157-165. doi:10.1093/geront/16.2.157 
Tremayne, P., Burdett, J., \& Utecht, C. (2011). Simulation suit aids tailored care. Nursing older people, 23(7), 19-22.

Tullo, E. S., Spencer, J., \& Allan, L. (2010). Systematic review: Helping the young to understand the old. Teaching interventions in geriatrics to improve the knowledge, skills, and attitudes of undergraduate medical students. Journal of the American Geriatrics Society, 58(10), 1987-1993. doi:10.1111/j.1532-5415.2010.03072.x

van Andel, S., Cole, M. H., \& Pepping, G.-J. (2017). A systematic review on perceptualmotor calibration to changes in action capabilities. Human Movement Science, 51, 5971. doi:10.1016/j.humov.2016.11.004

Voelcker-Rehage, C. (2008). Motor-skill learning in older adults—a review of studies on agerelated differences. European Review of Aging and Physical Activity, 5(1), 5-16. doi:10.1007/s11556-008-0030-9

Wechsler, D. (1981). Wechsler Adult Intelligence Scale - Revised (WAIS-R). New York: Psychological Corporation.

Wilhelm, P., \& Schoebi, D. (2007). Assessing Mood in Daily Life. Structural Validity, Sensitivity to Change, and Reliability of a Short-Scale to Measure Three Basic Dimensions of Mood. European Journal of Psychological Assessment, 23(4), 258267. doi:10.1027/1015-5759.23.4.258

Wood, M. D. (2003). Experiential Learning for Undergraduates. Gerontology \& Geriatrics Education, 23(2), 37-48. doi:10.1300/J021v23n02_03

Woollacott, M., \& Shumway-Cook, A. (2002). Attention and the control of posture and gait: a review of an emerging area of research. Gait and Posture, 16(1), 1-14. doi:10.1016/S0966-6362(01)00156-4

Yeudall, L. T., Fromm, D., Reddon, J. R., \& Stefanyk, W. O. (1986). Normative data stratified by age and sex for 12 neuropsychological tests. Journal of Clinical Psychology, 42, 918-946. 
Zijlstra, E., Hagedoorn, M., Krijnen, W. P., van der Schans, C. P., \& Mobach, M. P. (2016).

Route complexity and simulated physical ageing negatively influence wayfinding. Applied Ergonomics, 56, 62-67. doi:10.1016/j.apergo.2016.03.009 


\section{Appendices}

Table 1

Means and standard deviations for the six subtests of the Functional Fitness test for the female and male participants wearing the Suit, compared to normative data from Rikli and Jones (1999b, p. 169) for older adults. Note that, normative data for hip and shoulder flexibility are modified, by using centimeters instead of inches.

\begin{tabular}{|c|c|c|c|c|c|c|c|c|c|c|}
\hline Gender & Subtasks & $\begin{array}{l}\text { No } \\
\text { Suit }\end{array}$ & Suit & $\begin{array}{c}\text { Change } \\
(\%)\end{array}$ & $\begin{array}{l}60-64 \\
\text { years }\end{array}$ & $\begin{array}{l}65-69 \\
\text { years } \\
\end{array}$ & $\begin{array}{l}70-74 \\
\text { years } \\
\end{array}$ & $\begin{array}{l}75-79 \\
\text { years }\end{array}$ & $\begin{array}{l}80-84 \\
\text { years }\end{array}$ & $\begin{array}{l}85-89 \\
\text { years }\end{array}$ \\
\hline \multirow[t]{6}{*}{ Female } & $\begin{array}{l}\text { Leg strength } \\
\text { (n) }\end{array}$ & $\begin{array}{l}27.0 \\
(4.0)\end{array}$ & $\begin{array}{l}21.7 \\
(3.3)\end{array}$ & $\begin{array}{l}-19.4 \\
(6.3)\end{array}$ & $\begin{array}{l}14.5 \\
(4.0)\end{array}$ & $\begin{array}{l}13.5 \\
(3.5)\end{array}$ & $\begin{array}{l}12.9 \\
(3.6)\end{array}$ & $\begin{array}{l}12.5 \\
(3.8)\end{array}$ & $\begin{array}{l}11.3 \\
(4.2)\end{array}$ & $\begin{array}{l}10.3 \\
(4.0)\end{array}$ \\
\hline & $\begin{array}{l}\text { Arm strength } \\
\text { (n) }\end{array}$ & $\begin{array}{l}19.7 \\
(2.9)\end{array}$ & $\begin{array}{l}16.6 \\
(3.5)\end{array}$ & $\begin{array}{l}-16.2 \\
(10.6)\end{array}$ & $\begin{array}{l}16.1 \\
(4.6)\end{array}$ & $\begin{array}{l}15.2 \\
(4.3)\end{array}$ & $\begin{array}{l}14.5 \\
(4.4)\end{array}$ & $\begin{array}{l}14.0 \\
(4.4)\end{array}$ & $\begin{array}{l}13.0 \\
(4.1)\end{array}$ & $\begin{array}{l}12.2 \\
(3.8)\end{array}$ \\
\hline & $\begin{array}{c}\text { Aerobic } \\
\text { endurance (n) }\end{array}$ & $\begin{array}{l}122.4 \\
(12.4)\end{array}$ & $\begin{array}{c}93.5 \\
(13.5)\end{array}$ & $\begin{array}{l}-23.5 \\
(8.8)\end{array}$ & $\begin{array}{c}91 \\
(24)\end{array}$ & $\begin{array}{c}90 \\
(26)\end{array}$ & $\begin{array}{r}84 \\
(25)\end{array}$ & $\begin{array}{r}84 \\
(24)\end{array}$ & $\begin{array}{r}75 \\
(23)\end{array}$ & $\begin{array}{c}70 \\
(22)\end{array}$ \\
\hline & $\begin{array}{l}\text { Hip flexibility } \\
\text { (cm) }\end{array}$ & $\begin{array}{l}25.7 \\
(6.5)\end{array}$ & $\begin{array}{l}21.2 \\
(5.4)\end{array}$ & $\begin{array}{l}-17.0 \\
(12.1)\end{array}$ & $\begin{array}{c}5.3 \\
(10.2)\end{array}$ & $\begin{array}{c}5.1 \\
(9.1)\end{array}$ & $\begin{array}{c}3.6 \\
(9.4)\end{array}$ & $\begin{array}{c}3.0 \\
(9.7)\end{array}$ & $\begin{array}{c}1.3 \\
(9.4)\end{array}$ & $\begin{array}{l}-0.3 \\
(9.4)\end{array}$ \\
\hline & $\begin{array}{c}\text { Shoulder } \\
\text { flexibility }(\mathrm{cm})\end{array}$ & $\begin{array}{c}7.1 \\
(5.5)\end{array}$ & $\begin{array}{l}-3.3 \\
(6.5)\end{array}$ & $\begin{array}{l}-222.0 \\
(153.5)\end{array}$ & $\begin{array}{l}-1.8 \\
(8.9)\end{array}$ & $\begin{array}{l}-3.0 \\
(9.4)\end{array}$ & $\begin{array}{l}-4.3 \\
(9.7)\end{array}$ & $\begin{array}{c}-5.3 \\
(10.4)\end{array}$ & $\begin{array}{c}-6.6 \\
(10.7)\end{array}$ & $\begin{array}{c}-9.9 \\
(11.4)\end{array}$ \\
\hline & $\begin{array}{c}\text { Balance/ } \\
\text { Agility (s) }\end{array}$ & $\begin{array}{c}3.6 \\
(0.3)\end{array}$ & $\begin{array}{c}4.4 \\
(0.4)\end{array}$ & $\begin{array}{l}-23.5 \\
(5.2)\end{array}$ & $\begin{array}{c}5.2 \\
(1.2)\end{array}$ & $\begin{array}{c}5.6 \\
(1.2)\end{array}$ & $\begin{array}{c}6.0 \\
(1.6)\end{array}$ & $\begin{array}{c}6.3 \\
(1.6)\end{array}$ & $\begin{array}{c}7.2 \\
(2.2)\end{array}$ & $\begin{array}{c}7.9 \\
(2.5)\end{array}$ \\
\hline \multirow[t]{6}{*}{ Male } & $\begin{array}{l}\text { Leg strength } \\
\text { (n) }\end{array}$ & $\begin{array}{l}27.6 \\
(4.9)\end{array}$ & $\begin{array}{l}23.7 \\
(4.1)\end{array}$ & $\begin{array}{l}-13.1 \\
(13.9)\end{array}$ & $\begin{array}{l}16.4 \\
(4.3)\end{array}$ & $\begin{array}{l}15.2 \\
(4.5)\end{array}$ & $\begin{array}{l}14.5 \\
(4.2)\end{array}$ & $\begin{array}{l}14.0 \\
(4.3)\end{array}$ & $\begin{array}{l}12.4 \\
(3.9)\end{array}$ & $\begin{array}{l}11.1 \\
(4.6)\end{array}$ \\
\hline & $\begin{array}{l}\text { Arm strength } \\
\text { (n) }\end{array}$ & $\begin{array}{l}23.5 \\
(4.3)\end{array}$ & $\begin{array}{l}20.6 \\
(3.9)\end{array}$ & $\begin{array}{l}-12.0 \\
(7.4)\end{array}$ & $\begin{array}{l}19.0 \\
(4.7)\end{array}$ & $\begin{array}{l}18.4 \\
(5.3)\end{array}$ & $\begin{array}{l}17.4 \\
(5.0)\end{array}$ & $\begin{array}{l}16.2 \\
(4.6)\end{array}$ & $\begin{array}{l}16.0 \\
(4.3)\end{array}$ & $\begin{array}{l}13.6 \\
(4.3)\end{array}$ \\
\hline & $\begin{array}{c}\text { Aerobic } \\
\text { endurance (n) }\end{array}$ & $\begin{array}{l}130.5 \\
(13.4)\end{array}$ & $\begin{array}{l}107.5 \\
(10.5)\end{array}$ & $\begin{array}{l}-17.5 \\
(4.4)\end{array}$ & $\begin{array}{l}101 \\
(21)\end{array}$ & $\begin{array}{l}101 \\
(23)\end{array}$ & $\begin{array}{r}95 \\
(23)\end{array}$ & $\begin{array}{c}91 \\
(27)\end{array}$ & $\begin{array}{c}87 \\
(24)\end{array}$ & $\begin{array}{r}75 \\
(24)\end{array}$ \\
\hline & $\begin{array}{l}\text { Hip flexibility } \\
\text { (cm) }\end{array}$ & $\begin{array}{c}17.8 \\
(10.3)\end{array}$ & $\begin{array}{c}14.8 \\
(12.3)\end{array}$ & $\begin{array}{l}-26.1 \\
(37.3)\end{array}$ & $\begin{array}{c}1.5 \\
(12.2)\end{array}$ & $\begin{array}{c}0.0 \\
(11.7)\end{array}$ & $\begin{array}{c}-1.0 \\
(11.7)\end{array}$ & $\begin{array}{c}-2.8 \\
(11.9)\end{array}$ & $\begin{array}{c}-5.1 \\
(12.7)\end{array}$ & $\begin{array}{c}-6.1 \\
(10.7)\end{array}$ \\
\hline & $\begin{array}{c}\text { Shoulder } \\
\text { flexibility }(\mathrm{cm})\end{array}$ & $\begin{array}{c}2.8 \\
(9.3)\end{array}$ & $\begin{array}{l}-10.4 \\
(12.0)\end{array}$ & $\begin{array}{l}-350.2 \\
(553.3)\end{array}$ & $\begin{array}{c}-8.6 \\
(12.2)\end{array}$ & $\begin{array}{l}-10.4 \\
(12.4)\end{array}$ & $\begin{array}{l}-11.4 \\
(12.4)\end{array}$ & $\begin{array}{l}-14.2 \\
(13.0)\end{array}$ & $\begin{array}{l}-14.5 \\
(13.7)\end{array}$ & $\begin{array}{l}-15.7 \\
(12.2)\end{array}$ \\
\hline & $\begin{array}{c}\text { Balance/ } \\
\text { Agility (s) }\end{array}$ & $\begin{array}{c}3.3 \\
(0.3)\end{array}$ & $\begin{array}{c}4.1 \\
(0.5)\end{array}$ & $\begin{array}{l}-22.3 \\
(8.2)\end{array}$ & $\begin{array}{c}4.7 \\
(1.3)\end{array}$ & $\begin{array}{c}5.1 \\
(1.2)\end{array}$ & $\begin{array}{c}5.3 \\
(1.3)\end{array}$ & $\begin{array}{c}5.9 \\
(1.9)\end{array}$ & $\begin{array}{c}6.4 \\
(1.8)\end{array}$ & $\begin{array}{c}7.2 \\
(2.6)\end{array}$ \\
\hline
\end{tabular}


Note. $\mathrm{n}=$ numbers, $\mathrm{cm}=$ centimeters, $\mathrm{s}=$ seconds.

Negative values for the \%-change measure indicate performance deteriorations in the suit-condition. 
Table 2

Means and standard deviations for the four subtests of the Purdue Pegboard test for the female and male participants wearing the Suit, compared to normative data from Agnew et al. (1988, p. 32) for older adults

\begin{tabular}{|c|c|c|c|c|c|c|c|c|}
\hline Gender & Subtasks & $\begin{array}{l}\text { No } \\
\text { Suit }\end{array}$ & Suit & $\begin{array}{c}\text { Change } \\
(\%)\end{array}$ & $\begin{array}{l}50-59 \\
\text { years }\end{array}$ & $\begin{array}{l}60-69 \\
\text { years }\end{array}$ & $\begin{array}{l}70-79 \\
\text { years }\end{array}$ & $\begin{array}{l}80-89 \\
\text { years }\end{array}$ \\
\hline \multirow[t]{4}{*}{ Female } & $\begin{array}{l}\text { Dominant hand } \\
\text { (n) }\end{array}$ & $\begin{array}{c}17.3 \\
(1.47)\end{array}$ & $\begin{array}{c}12.8 \\
(0.95)\end{array}$ & $\begin{array}{l}-25.6 \\
(6.74)\end{array}$ & $\begin{array}{c}15.0 \\
(1.56)\end{array}$ & $\begin{array}{c}14.6 \\
(2.03)\end{array}$ & $\begin{array}{c}13.8 \\
(1.27)\end{array}$ & $\begin{array}{c}12.9 \\
(1.80)\end{array}$ \\
\hline & $\begin{array}{l}\text { Non-dominant } \\
\text { hand (n) }\end{array}$ & $\begin{array}{c}15.8 \\
(2.01)\end{array}$ & $\begin{array}{c}12.0 \\
(1.67)\end{array}$ & $\begin{array}{l}-23.6 \\
(9.04)\end{array}$ & $\begin{array}{c}14.4 \\
(1.69)\end{array}$ & $\begin{array}{c}13.9 \\
(1.78)\end{array}$ & $\begin{array}{c}12.9 \\
(1.52)\end{array}$ & $\begin{array}{c}11.3 \\
(2.05)\end{array}$ \\
\hline & $\begin{array}{l}\text { Both hands } \\
\text { (n of pairs) }\end{array}$ & $\begin{array}{c}13.9 \\
(1.40)\end{array}$ & $\begin{array}{c}9.8 \\
(1.81)\end{array}$ & $\begin{array}{c}-29.4 \\
(10.17)\end{array}$ & $\begin{array}{c}12.1 \\
(1.30)\end{array}$ & $\begin{array}{c}11.6 \\
(1.87)\end{array}$ & $\begin{array}{c}10.5 \\
(1.19)\end{array}$ & $\begin{array}{c}9.2 \\
(1.92)\end{array}$ \\
\hline & $\begin{array}{l}\text { Assembly } \\
\text { (n) }\end{array}$ & $\begin{array}{c}39.4 \\
(6.69)\end{array}$ & $\begin{array}{c}25.8 \\
(7.61)\end{array}$ & $\begin{array}{c}-35.5 \\
(12.14)\end{array}$ & $\begin{array}{c}34.6 \\
(8.21)\end{array}$ & $\begin{array}{c}31.7 \\
(6.83)\end{array}$ & $\begin{array}{c}29.1 \\
(4.85)\end{array}$ & $\begin{array}{c}21.9 \\
(4.54)\end{array}$ \\
\hline \multirow[t]{4}{*}{ Male } & $\begin{array}{l}\text { Dominant hand } \\
\text { (n) }\end{array}$ & $\begin{array}{c}15.3 \\
(1.85)\end{array}$ & $\begin{array}{c}12.2 \\
(1.90)\end{array}$ & $\begin{array}{c}-19.8 \\
(10.60)\end{array}$ & $\begin{array}{c}14.4 \\
(2.15)\end{array}$ & $\begin{array}{c}13.6 \\
(1.74)\end{array}$ & $\begin{array}{c}13.0 \\
(1.90)\end{array}$ & $\begin{array}{c}10.8 \\
(1.33)\end{array}$ \\
\hline & $\begin{array}{l}\text { Non-dominant } \\
\text { hand (n) }\end{array}$ & $\begin{array}{c}14.6 \\
(1.25)\end{array}$ & $\begin{array}{c}11.5 \\
(1.36)\end{array}$ & $\begin{array}{l}-21.6 \\
(7.91)\end{array}$ & $\begin{array}{c}13.9 \\
(2.19)\end{array}$ & $\begin{array}{c}13.1 \\
(1.56)\end{array}$ & $\begin{array}{c}12.4 \\
(1.48)\end{array}$ & $\begin{array}{c}10.6 \\
(1.84)\end{array}$ \\
\hline & $\begin{array}{l}\text { Both hands } \\
\text { (n of pairs) }\end{array}$ & $\begin{array}{c}11.8 \\
(1.17)\end{array}$ & $\begin{array}{c}9.1 \\
(1.28)\end{array}$ & $\begin{array}{l}-23.3 \\
(6.26)\end{array}$ & $\begin{array}{c}11.9 \\
(2.22)\end{array}$ & $\begin{array}{c}10.9 \\
(1.46)\end{array}$ & $\begin{array}{c}10.4 \\
(1.27)\end{array}$ & $\begin{array}{c}8.5 \\
(1.21)\end{array}$ \\
\hline & $\begin{array}{l}\text { Assembly } \\
\text { (n) }\end{array}$ & $\begin{array}{c}34.7 \\
(6.86) \\
\end{array}$ & $\begin{array}{c}24.3 \\
(5.51)\end{array}$ & $\begin{array}{l}-30.2 \\
(7.25) \\
\end{array}$ & $\begin{array}{c}33.8 \\
(9.66)\end{array}$ & $\begin{array}{r}28.0 \\
(5.06) \\
\end{array}$ & $\begin{array}{r}27.5 \\
(5.06) \\
\end{array}$ & $\begin{array}{r}21.5 \\
(4.81) \\
\end{array}$ \\
\hline
\end{tabular}

Note. $\mathrm{n}=$ numbers.

Negative values for the \%-change measure indicate performance deteriorations in the suit-condition. 
Table 3

Main effects and interaction effects for all dimensions of the Perceived Physical State and the Mood State-questionnaires

\begin{tabular}{|c|c|c|c|c|c|}
\hline Questionnaires & Dimensions & Effects & Df-value & F-value & $\begin{array}{c}\text { Partial eta } \\
\text { square }\end{array}$ \\
\hline \multirow{12}{*}{$\begin{array}{l}\text { Perceived } \\
\text { Physical } \\
\text { State }\end{array}$} & \multirow[t]{3}{*}{ Energy } & Suit & \multirow{3}{*}{$(1,17)$} & $20.17 * * *$ & .54 \\
\hline & & Order & & $40.77 * * *$ & .71 \\
\hline & & Suit x Order & & $26.50 * * *$ & .61 \\
\hline & \multirow[t]{3}{*}{ Fitness } & Suit & \multirow{3}{*}{$(1,17)$} & $26.23^{* * *}$ & .61 \\
\hline & & Order & & $28.97 * * *$ & .63 \\
\hline & & Suit x Order & & $17.97 * *$ & .51 \\
\hline & \multirow[t]{3}{*}{ Flexibility } & Suit & \multirow{3}{*}{$(1,17)$} & $4.55 *$ & .21 \\
\hline & & Order & & $9.23 * *$ & .35 \\
\hline & & Suit x Order & & $19.87 * * *$ & .54 \\
\hline & \multirow[t]{3}{*}{ Health } & Suit & & $6.28 *$ & .27 \\
\hline & & Order & $(1,17)$ & $9.73 * *$ & .36 \\
\hline & & Suit x Order & & $12.37 * *$ & .42 \\
\hline \multirow{9}{*}{$\begin{array}{l}\text { Mood } \\
\text { State }\end{array}$} & \multirow{3}{*}{$\begin{array}{c}\text { Energetic } \\
\text { arousal }\end{array}$} & Suit & \multirow{3}{*}{$(1,17)$} & $16.43 * *$ & .49 \\
\hline & & Order & & 1.24 & .07 \\
\hline & & Suit x Order & & $6.83 *$ & .29 \\
\hline & \multirow{3}{*}{ Valence } & Suit & \multirow{3}{*}{$(1,17)$} & $29.32 * * *$ & .63 \\
\hline & & Order & & $15.87 * *$ & .48 \\
\hline & & Suit x Order & & $30.29 * * *$ & .64 \\
\hline & \multirow{3}{*}{ Calmness } & Suit & \multirow{3}{*}{$(1,17)$} & $6.89 *$ & .29 \\
\hline & & Order & & $9.87 * *$ & .37 \\
\hline & & Suit x Order & & $23.50 * * *$ & .58 \\
\hline
\end{tabular}

Note. ${ }^{*}=\mathrm{p}<.05,{ }^{* *} \mathrm{p}<.01, * * *=\mathrm{p}<.001$. 


\section{Figures}

Figure 1. The Age Simulation Suit GERT.

Figure 2. Comparisons of the Suit- (light gray) and No Suit-condition (dark gray) for all subtests of the Functional Fitness test (Strength, Aerobic endurance, Flexibility and Balance/Agility), the Purdue Pegboard test (Dominant hand, Non-dominant hand, Both hands and Assembly) and the Digit Symbol Substitution test (Score). Changes from the beginning to the middle of the sessions in Mood State (dimensions: Energetic arousal, Valence and Calmness) and Physical State (dimensions: Activation, Training, Flexibility and Health) are displayed only for the Suit-condition. All results are represented by the means and their respective standard errors. 


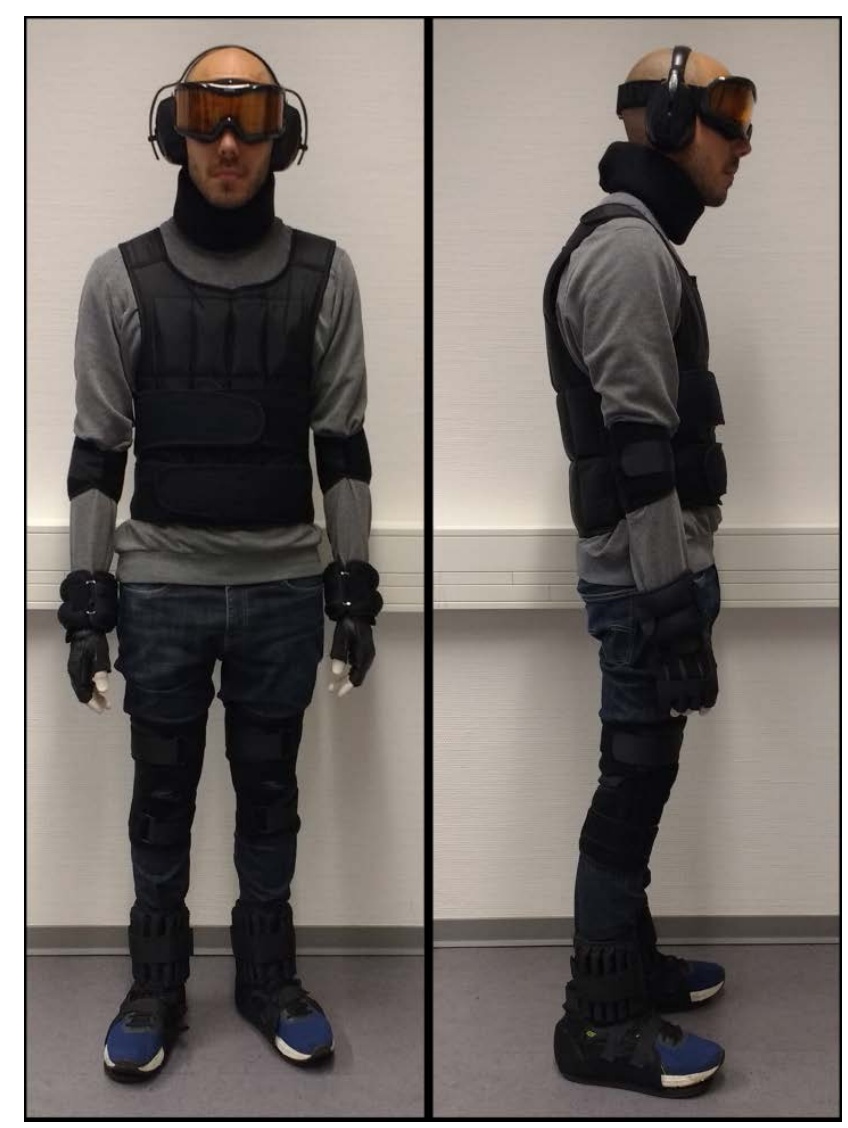

Figure 1. 


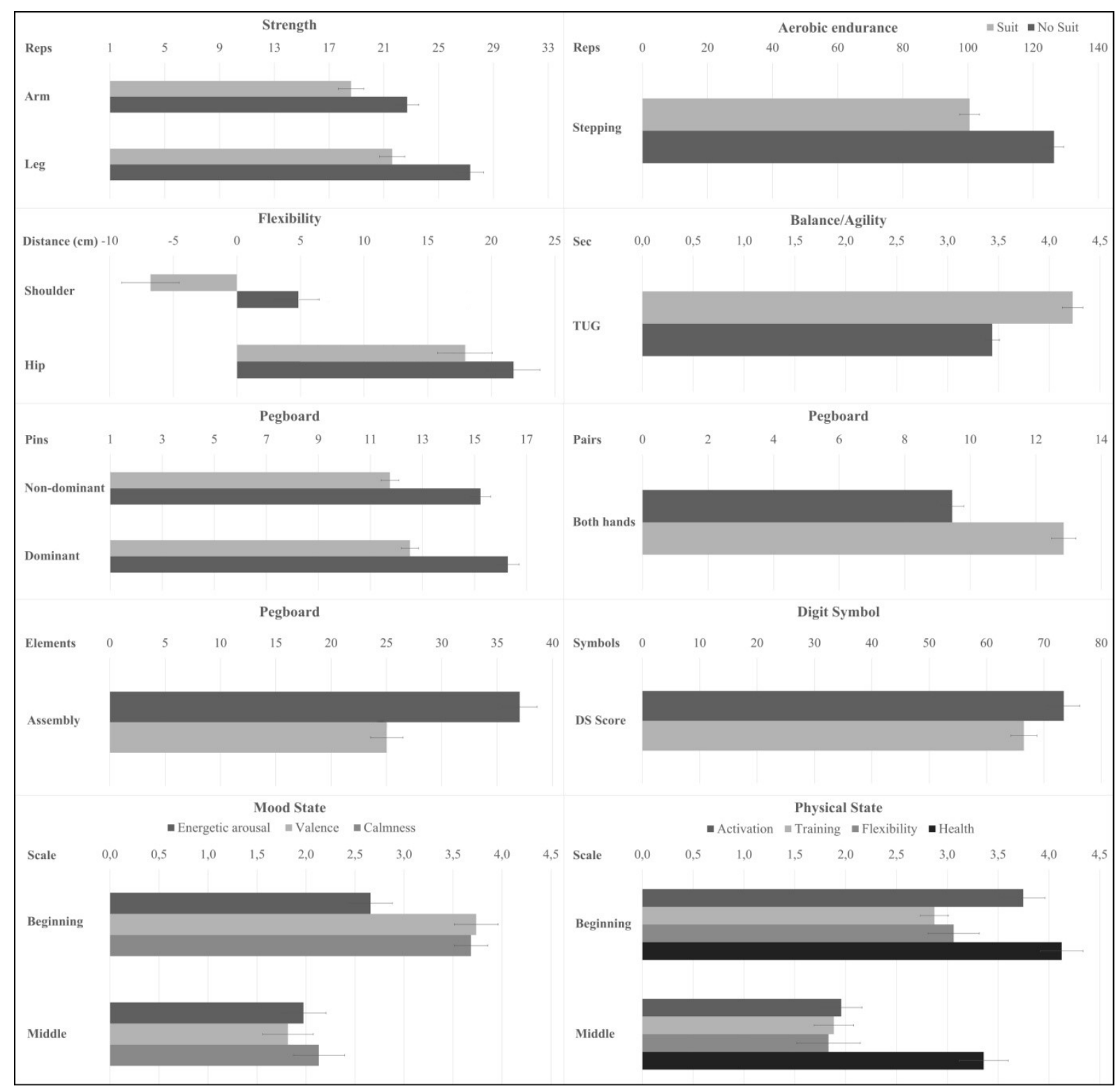

Figure 2. 